\section{Thomas Szasz}

Thomas Szasz is Professor emeritus of Psychiatry at the State University of New York. He trained at the Universities of Cincinnati and Chicago and the Chicago Institute for Psychoanalysis. His special interests are reading and writing about the history of psychiatry, psychiatry and law, and psychiatry and ethics.

If you were not a psychiatrist, what would you do?

Basic medical research, physics, or chemistry.

What has been the greatest impact of your profession on you personally? Confirming my conviction that personal responsibility and individual liberty are the highest human values

Do you feel stigmatised by your profession? No.

What are your interests outside of work?

Family, reading and walking.

Who was your most influential trainer?

No one.

What job gave you the most useful training experience?

Private practice of autonomous

psychotherapy.

Which book/text has influenced you most?

An Essay Concerning Human

Understanding, by John Locke.

What research publication has had the greatest influence on your work? None.

What part of your work gives you the most satisfaction?

Writing.

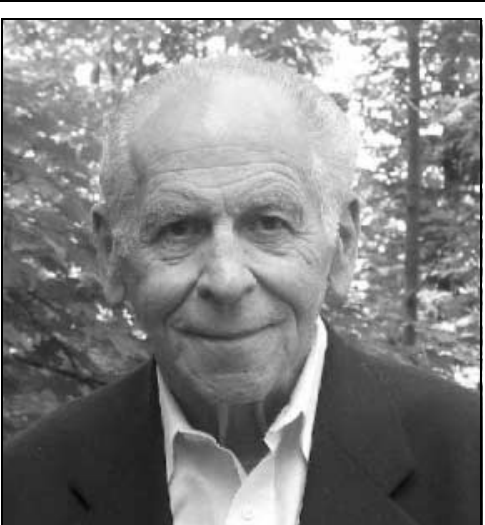

What do you least enjoy?

Hearing psychiatric propaganda, such as 'Mental diseases are brain diseases'.

What is the most promising opportunity facing the profession? Recognising its betrayal of patient trust and rejecting the role of the psychiatrist as agent of social control.

What is the greatest threat?

Accepting and enlarging the role of the psychiatrist as agent of social control.

What single change would substantially improve quality of care? The abolition of all psychiatric coercions and excuses.

What conflict of interest do you encounter most often?

I am 84 years-old and retired. When I was active the most common conflict of interest was the professional pressure to betray the patient's confidence and trust and act in opposition to his self-defined interests.

Do you think psychiatry is brainless or mindless?

Both.

How would you entice more medical students into the profession? I wouldn't.
What is the most important advice you could offer to a new trainee?

Never coerce or excuse patients, or, get out of the field.

What are the main ethical problems that psychiatrists will face in the future?

The same ones they refuse to face today.

How would you improve clinical psychiatric training?

I wouldn't. There is nothing 'clinical' about it

What single change to mental health legislation would you like to see? The abolition of all 'mental health legislation'.

How should the roles of the Royal College of Psychiatrists and the American Psychiatric Association change?

These organisations (and other mental health groups) ought to split into two distinct associations, according to their members' practices - one group composed of practitioners serving the patient's self-determined interests, the other group serving the interests of individuals and institutions seeking to control the patient.

What is the future for psychotherapy in psychiatry training and practice? Dismal.

What single area of psychiatric research should be given priority? Research into, and full disclosure of, the area of psychiatry most concealed from both professional and public view - the beliefs and behaviours of psychiatrists.

What single area of psychiatric practice is most in need of development? The demedicalisation and deprofessionalisation of the secular cure of souls and its separation from the state (independence from the criminal justice system and no public funding for services).

Dominic Fannon 